\title{
Several Important Points of Realizing the Connotative Development of Higher Vocational Education in the New Era
}

\author{
Chen $\mathrm{Yu}^{1, \mathrm{a}}$, Wang Jiajia ${ }^{1, \mathrm{~b}}$ \\ ${ }^{1}$ Taizhou Polytechnic College, Jiangsu Taizhou, China, 225300 \\ axiaoyueryuchen@163.com bwangjiajia_99@163.com
}

Keywords: New era, Higher vocational education, Connotative development

\begin{abstract}
The necessary way of higher vocational education in the new era is the connotative development. It is necessary to accurately grasp its essential characteristics and internal requirements, adhere to the initial heart of higher vocational education, speed up the modernization of higher vocational education, and strengthen the party building in higher vocational colleges, deepen the comprehensive management of schools in accordance with the law, focus on the key links and exertive accurately.
\end{abstract}

\section{Introduction}

New era, new mission. After socialism with Chinese characteristics entered a new era, higher vocational education ushered in a new situation, new challenges and new tasks. How to adapt quickly to the requirements of the new era and effectively solve the problems of the new era, to bid farewell to the extensive development mode of "scale is king" and to enter the elaborate development mode of "connotation is king" is the most important issue that must be paid close attention .

\section{Realizing connotative development is the necessary way of higher vocational education in} the new era

In the report by 19th CPC National Congress of the Party, General Secretary Xi Jinping clearly pointed out that after a long period of efforts, socialism with Chinese characteristics has entered a new era, which is a new historical orientation for China's economic and social development. He also stressed in particular, socialism with Chinese characteristics has entered a new era, and the principal social contradictions in our country have been transformed into the contradictions between the growing needs of the people for a better life and the unbalanced and inadequate development. ${ }^{[1]}$ The changes of the principal contradictions in society are historical changes related to the overall situation. The main social contradictions have changed, and so must the work of the Party and the country. The development of education and higher vocational education is the same. As an important part of social undertakings, higher vocational education has a strong "people's livelihood" attribute. It plays an important role in ensuring and improving people's livelihood, and is an extremely important part of "the people's growing need for a better life."

However, after entering the new era, higher vocational education, like other undertakings, also has the problem of the unbalanced and inadequate development, which conflicts with meeting the "growing needs of the people for a better life". Therefore, in the report by 19th CPC National Congress of the Party, General Secretary Xi Jinping explicitly proposed "realizing the connotative development of higher education", which pointed out the direction for the development of higher vocational education in the new era. ${ }^{[2]}$ This is not only the lofty mission of all higher education, including higher vocational education, given by the CPC Central Committee with Comrade Xi Jinping as the core, but also the most fundamental and urgent essential requirement of higher vocational education after entering the new era. To solve the problems of unbalanced and inadequate in the development of higher vocational education, to better meet the "people's growing need for a better life", it is necessary to shift the emphasis of development from "scale expansion" to "quality 
improvement", and make every effort to promote the connotative development of higher vocational education.

\section{The Internal characteristics and requirements of the connotative development of higher vocational education in the new era}

Since always, although higher vocational education has always stressed the connotation construction in development, but in practice it consciously or unconsciously to the excessive inclination towards extension, the phenomenon of attaching importance to extension and neglecting connotation is quite universal. Especially due to the late start, rapid development, and limited strength in running a school, can not take into account effectively, the quality of connotation construction and the speed of extension development obviously do not match. Chinese higher vocational education started in the last century in $80 \mathrm{~s}$, much later than other traditional universities, but after just 30 years of development, the number of schools and the number of students have been greatly more than half of the higher education in our country. Especially in the higher vocational education in the modern sense, mainly concentrated in the last century at the end of 90 s, it was only 20 years ago. ${ }^{[2]}$ Due to the development time is short, the development speed is fast, many higher vocational colleges blindly pursue the visible hardware, often ignore the connotation construction, leading to the unknown characteristics, not many bright spots, can be said that in addition to scale, the other is not prominent, a few public and some private vocational colleges also suffered a crisis of survival. In recent years, Anhui, Shanxi, Shandong, Jiangsu and so on, some higher vocational colleges in many parts suffered serious difficulty of enrollment, although there are many factors, but one of the most important, the connotation is not thick, the quality is not high.

At the same time, the higher vocational education of our country is rising rapidly in the same frequency resonance with the economic and social development, and it inevitably produces path dependence on the former extensive economic and social development mode. The development of higher vocational education is a microcosm of our country's economic and social development. From "scale is king" to "connotation is king". In the past, the extension mode of development emphasized the scale, sought to survive and gain benefit with the rapid expansion of the scale. However, the current connotation development mode must pay attention to the quality. Take the rapid improvement of quality as the basic premise, realize the dialectical unity and coordinated development of scale, quality, structure and benefit, coordinate the development. Only with quality improvement as the core, strictly control the expansion of scale, make it always within a reasonable range, ensuring the effective convergence and integrated development model of the expansion of scale, the improvement of quality, structural optimization and benefit increase, this is the intrinsic characteristics of connotation development. At the same time, this is also the internal requirement to solve the imbalance of supply and demand structure and the mismatch of dispensing, and to solve the serious shortage of high quality higher vocational education resources.

\section{The main focus of the connotation development of higher vocational education in the new era.}

To realize the connotation development of higher vocational education in the new era is a complex system engineering, which requires full effort, long time work, same direction, same frequency resonance, and also needs to grasp the key points, highlight the key points, let one unit guide a whole area, blooming in an all-round way. Especially in the comprehensive opening stage, we must systematically plan, promote integrally, and earnestly find out the most important points, make the best use of our limited strength, and take the lead in making key breakthroughs in key areas, give full play to the leading role of the Commander-in-Chief. At present, the most important thing is to hold high at all times the great banner of Xi Jinping's socialist thinking with Chinese characteristics in the new era. Do well the "four more" meticulously, try hard to open the new journey of building the 
modern higher vocational education in an all-round way, and compose the better chapter of the times of the higher vocational education meticulously.

\subsection{Pushing forward the development of higher vocational education with a firmer mind.}

The 19th CPC National Congress's report began in pointing out the theme of the conference: never forget the original mind, remember the mission. Indeed, The very beginning mind itself is the most accomplished mind of true enlightenment. The initial heart of the higher vocational college is the fundamental motive force to promote the development of career. To hold high the great banner of Xi Jinping's socialist thinking with Chinese characteristics in the new era, the first important thing is to be more firm the initial heart, to forge ahead, to constantly improve and to upgrade oneself. Only in this way, it is possible to settle down quietly, abandon impetuosity, remove all kinds of temptations and outside interference, and take the road of development of higher vocational education with Chinese characteristics. It is needless to say that the development of higher vocational education is faced with various difficulties and problems. All kinds of evaluation methods in government departments or in the private sector will bring great pressure to higher vocational colleges. Many higher vocational colleges often adopt a short, flat, and quick utilitarian approach to deal with this, but this is totally undesirable. In order to truly realize the connotation development, we must overcome short-term behavior and utilitarian tendencies, firmly establish the concept of fighting a protracted war, take all things into consideration, base ourselves on reality, stick to our initial mind, maintain our determination, show our characteristics, and hold fast to deep-seated and fundamental problems, and tackle the key problems bit by bit, one by one. We should thoroughly reflect on the problems existing in such aspects as the idea of running a school, the campus culture, the training model, the teaching method, etc., tap the potential, clear away the hidden dangers, and constantly break through the bottleneck of the system and mechanism. Full of confidence to walk out of a development road with its own characteristics. Otherwise, it will inevitably take stop - gap measures, follow one's steps, and suffer from gain and loss, for the sake of short-term interests and misguided.

\subsection{Promoting the modernization of higher vocational education with more conscious action.}

$\mathrm{Xi}$ Jinping's thought of socialism with Chinese characteristics in the new era, as the latest theoretical achievement of the Sinicization of Marxism, has been innovated according to the distinctive characteristics of the great cause and new practice of the new era, to the economy, politics, culture, education and other aspects have made thorough theoretical analysis and policy guidance, which is the fundamental magic weapon for us to do a good job in higher vocational education. The General Secretary has profoundly expounded its spiritual essence and rich connotation. In particular, it is pointed out that "upholding the people as the center" is one of the 14 basic strategies for upholding and developing socialism with Chinese characteristics in the new era, It is emphasized that "the people's yearning for a better life" should be taken as the goal of struggle, and give priority to the development of education as the primary task of " improving the level of livelihood security and improvement of the people's livelihood." For higher vocational colleges, in order to implement the spirit of 19th CPC National Congress of the Party, we must fully implement the Party's educational policy, take the establishment of morality as a fundamental task, and train the socialist constructors and successors who have fully developed morality, wisdom, body and aesthetic. In particular, we must make greater efforts to deepen the integration of industry and education and cooperation between schools and enterprises in the light of their respective realities. Speed up the cultivation of more high-quality technical skills, with more conscious action to speed up the modernization of higher vocational education, run a satisfactory higher vocational education.

\subsection{Promoting the Party building in higher vocational colleges with a more determined attitude.}

Party building is an important foundation for the overall work of colleges and universities and a fundamental guarantee for the development of their undertakings, it has always played a fundamental 
and decisive role. In the report by 19th CPC National Congress, General Secretary Xi Jinping according to the new requirements of the new era, the general requirements for party building in the new era have been put forward. The most important of these is to bring the party's political construction into the overall layout of party building for the first time, to emphasize the leadership of political construction, and to comprehensively promote the party's political, ideological, organizational, work style and discipline construction, run through the construction of the system and push forward the fight against corruption in depth. It is a major innovation of Marxist Party building theory, it is also the fundamental guideline for the party building of all units, including higher vocational colleges. Higher vocational colleges must be guided by the basic strategy of Xi Jinping's socialist thought with Chinese characteristics in the new era of "adhering to a comprehensive and strict administration of the Party." In accordance with the specific requirements put forward by the General Secretary in the report, comprehensively combed out the shortcomings existing in the party building work and carried out rectification and reform one by one. In particular, it is necessary to focus on improving the level of running higher vocational education, with the goal of running a satisfactory higher vocational education among the people as its goal, to promote the Party building in higher vocational colleges with a more resolute attitude, to concentrate on the Party building and to concentrate on the development of the Party.

\subsection{Promoting the comprehensive management of higher vocational schools according to law with more effective measures.}

General Secretary Xi Jinping has repeatedly stressed that governing the country according to law is the basic way for the party to lead the people in running the country, and that the overall rule of law is the essential requirement and important guarantee of socialism with Chinese characteristics. It is also established as one of the 14 basic strategies of Xi Jinping's socialist thought with Chinese characteristics in the new era. To carry out this basic strategy and to realize the modernization of the governing system and governing ability of higher vocational colleges, it is necessary to promote the comprehensive management of higher vocational schools according to law, which is also the basic requirement and concrete practice of carrying out "overall rule of law" in higher vocational colleges, which must be guided by this basic strategy and the specific requirements of 19th CPC National Congress's report, to effectively improve the consultation decision-making, review, evaluation, command and execution, supervision and security mechanism of higher vocational colleges, clarify their responsibilities and powers, constantly optimize the internal governance structure, and promote the comprehensive administration of schools in accordance with the law with more effective measures, improve the rule of law and scientific degree of management in higher vocational colleges.

\section{Acknowledgement}

This article was financially supported by the Special Project of Ideological and Political Work on the Research of Philosophy and Social Science in Universities of Jiangsu(2017SJBFDY683), the Key Project of Scientific Research Fund of Taizhou Polytechnic College (TZYKYZD-17-4).

\section{References}

[1] Xi Jinping. To build a Well-off Society in an All-round way and win the Great Victory of Socialism with Chinese characteristics in the New era[C]// Book writing group, The party's 19th CPC National Congress Report Guide Book, Peking, people's publishing house, pp.11-45, 2017.

[2] Xu Shuping, Chen Yu. Some important issues to be paid attention to in improving the quality of higher Vocational Education[J], Vocational and Technical Education, vol.33, pp.29, 2015. 